\title{
Weight loss intervention for young adults using mobile technology: Design and rationale of a randomized controlled trial - Cell Phone Intervention for You (CITY)
}

Bryan C. Batch ${ }^{\text {a,b,* }}$, Crystal Tyson ${ }^{\text {b,c }}$, Jacqueline Bagwell ${ }^{\mathrm{b}}$, Leonor Corsino ${ }^{\mathrm{a}, \mathrm{b}}$, Stephen Intille ${ }^{\mathrm{d}, \mathrm{e}}$, Pao-Hwa Lin ${ }^{\text {b }}$, Tony Lazenka ${ }^{\mathrm{d}, \mathrm{e}}$, Gary Bennett ${ }^{\mathrm{f}, \mathrm{g}, \mathrm{h}}$, Hayden B. Bosworth ${ }^{\mathrm{i}, \mathrm{j}, \mathrm{k}, \mathrm{l}}$, Corrine Voils ${ }^{\mathrm{i}, \mathrm{j}}$, Steven Grambow ${ }^{\mathrm{i}, \mathrm{m}}$, Aziza Sutton ${ }^{\mathrm{b}}$, Rachel Bordogna ${ }^{\mathrm{b}}$, Matthew Pangborn ${ }^{\mathrm{b}}$, Jenifer Schwager ${ }^{\mathrm{b}}$, Kate Pilewski $^{\text {b }}$, Carla Caccia ${ }^{\text {b }}$, Jasmine Burroughs ${ }^{\text {b }}$, Laura P. Svetkey ${ }^{\mathrm{b}, \mathrm{c}}$

a Department of Medicine, Division of Endocrinology, Duke University Medical Center, DUMC Box 3921 Durham, NC 27710, USA

b Sarah W. Stedman Nutrition and Metabolism Center, 3475 Erwin Road, Duke University Medical Center, Durham, NC 27710, USA

c Department of Medicine, Division of Nephrology, Duke University Medical Center, DUMC Box 103105, Durham, NC 27710, USA

d College of Computer and Information Science, Northeastern University, 202 West Village H, Office 450, 360 Huntington Avenue, Boston, MA 02115, USA

e Bouvé College of Health Sciences, Northeastern University, 202 West Village H, Office 450, 360 Huntington Avenue, Boston, MA 02115, USA

${ }^{\mathrm{f}}$ Department of Psychology \& Neuroscience, Duke University Medical Center, Box 90086, 417 Chapel Drive, Duke University, Durham, NC 27708-0086, USA

g Duke Obesity Prevention Program, Duke University Medical Center, Durham, NC, USA

h Duke Global Health Institute, Duke University Medical Center, 310 Trent Drive, Durham, NC 27710, USA

${ }^{i}$ Center for Health Services Research in Primary Care, Durham Veterans Affairs Medical Center, 508 Fulton Street, Durham, NC 27705, USA

${ }^{\mathrm{j}}$ Department of Medicine, Division of General Internal Medicine, Duke University Medical Center, Box 3240, Durham, NC 27710, USA

${ }^{k}$ Department of Psychiatry, Duke University Medical Center, 2301 Erwin Road 27710 Durham, NC, USA

${ }^{1}$ Duke University School of Nursing, 307 Trent Drive, DUMC 3322, 27710, Durham, NC, USA

m Department of Biostatistics and Bioinformatics, Duke University Medical Center, DUMC Box 2721, Durham, NC 27710, USA

\section{A R T I C L E I N F O}

\section{Article history:}

Received 12 August 2013

Received in revised form 6 January 2014

Accepted 13 January 2014

Available online 21 January 2014

\section{Keywords:}

Obesity

Young adult

Weight loss

Mobile health

Technology

Behavioral intervention

\begin{abstract}
A B S T R A C T
Background: The obesity epidemic has spread to young adults, leading to significant public health implications later in adulthood. Intervention in early adulthood may be an effective public health strategy for reducing the long-term health impact of the epidemic. Few weight loss trials have been conducted in young adults. It is unclear what weight loss strategies are beneficial in this population.

Purpose: To describe the design and rationale of the NHLBI-sponsored Cell Phone Intervention for You (CITY) study, which is a single center, randomized three-arm trial that compares the impact on weight loss of 1 ) a behavioral intervention that is delivered almost entirely via cell phone technology (Cell Phone group); and 2) a behavioral intervention delivered mainly through monthly personal coaching calls enhanced by self-monitoring via cell phone (Personal Coaching group), each compared to 3 ) a usual care, advice-only control condition.

Methods: A total of 365 community-dwelling overweight/obese adults aged 18-35 years were randomized to receive one of these three interventions for 24 months in parallel group design. Study personnel assessing outcomes were blinded to group assignment. The primary outcome is weight change at 12 months. We hypothesize that each active intervention will cause more
\end{abstract}

\footnotetext{
* Corresponding author at: Duke University Medical Center, DUMC Box 3031, Durham, NC 27710, USA. Tel.: +1919 6681219 ; fax: + 19196819846. E-mail addresses: bryan.batch@duke.edu (B.C. Batch), crystal.simpson@duke.edu (C. Tyson), jacqueline.bagwell@fuqua.duke.edu (J. Bagwell), leonor.corsinonunez@dm.duke.edu (L. Corsino), S.Intille@neu.edu (S. Intille), pao.hwa.lin@dm.duke.edu (P.-H. Lin), tlazenka@gmail.com (T. Lazenka), gary.bennett@duke.edu (G. Bennett), hayden.bosworth@duke.edu (H.B. Bosworth), corrine.voils@duke.edu (C. Voils), steven.grambow@duke.edu (S. Grambow), aziza.sutton@duke.edu (A. Sutton), rachel.bordogna@gmail.com (R. Bordogna), matthew.pangborn@duke.edu (M. Pangborn), jennifer.schwager@duke.edu (J. Schwager), kate.pilewski@duke.edu (K. Pilewski), cdscaccia@gmail.com (C. Caccia), jasmine.burroughs@duke.edu (J. Burroughs), laura.svetkey@duke.edu (L.P. Svetkey).
} 
weight loss than the usual care condition. Study completion is anticipated in 2014.

Conclusions: If effective, implementation of the CITY interventions could mitigate the alarming rates of obesity in young adults through promotion of weight loss. ClinicalTrial.gov: NCT01092364.

Published by Elsevier Inc.

\section{Introduction}

Over $32 \%$ of the US population aged $20-35$ years is obese [1]. The most rapid weight gain occurs during the early adult years [2,3]. Weight gain in adults aged $18-30$ years is associated with almost 20 times greater risk of developing metabolic syndrome over the subsequent 15 years, compared to adults who maintain stable weight over that period of time [4]. Weight gain in early adulthood is also associated with increased coronary calcification in middle age [5], suggesting a causal link between increasing cardiovascular disease (CVD) risk factors with weight gain in young adults and subsequent risk of CVD events. These data suggest that weight control (i.e., weight loss in overweight and obese individuals and preventing weight gain in all individuals) during young adulthood can reduce future CVD risk factors and CVD events later in life. It is possible that healthy lifestyle changes early in adult life can create healthy behavior patterns that can be sustained throughout life [6].

Previous studies of behavioral interventions for weight control have generally included small numbers of young adults $[7,8]$, which limits generalizability of results. For example, the mean age of adults enrolled in the Weight Loss Maintenance (WLM) Trial was 54 years and only those greater than or equal to 25 years old were eligible [9]. Although young adults were included in the trial and participants across the age spectrum (25-83) lost weight, older participants ( $>60$ years) initially lost more weight than younger participants and sustained greater weight loss in both active intervention arms [10]. These results suggest that intervention design or delivery may need to be tailored based on age and stage in life.

Poobalan et al. [11] did a meta-analysis in order to systematically review evidence for weight loss interventions in 18 to 25 year olds between 1980 and March 2010. Fourteen studies were included in the review of which eight were exercise interventions, two were diet and exercise interventions, two were behavioral/motivational interventions, one was a combined intervention (diet/physical activity/behavioral skills), and one focused on use of conjugated linoleic acid. The number of participants in the studies ranged between 16 and 67 and the period for intervention delivery ranged from 2 weeks to 52 weeks. Across all studies, the mean weight loss with intervention was $-3.01 \mathrm{~kg}(95 \% \mathrm{CI}-8.5$ to 2.5$)$. The mean weight loss for the behavioral/motivational interventions was $-2.40 \mathrm{~kg}$ (95\% CI -5.4 to 0.6 ) and for combination interventions (diet/exercise/motivational skills) was $-2.96 \mathrm{~kg}$ (95\% CI 4.4 to -1.5 ). Although the weight lost was comparable across interventions, the results may not be generalizable as the trials were small and of short duration and the attrition rates were high. More research is needed in order to design effective weight loss interventions for young adults.
It may be speculated that relative to older adults, young adults relate less to future health problems associated with weight gain and may be more accustomed to immediate gratification, which may serve as barriers to weight loss. Other barriers to weight loss, which have been identified in qualitative studies, that are relevant to young adults include financial constraints making it difficult to meet the added costs of healthful behaviors (i.e., gym memberships, food expenses) and time constraints making it difficult to juggle health with behaviors competing with life priorities, such as, attending school, building a career, and starting a family [12-14]. It is worthwhile to consider new approaches to weight management in young adults that are designed to fit their lifestyles and circumstances. One such approach is use of mobile phone technology for delivery of a behavioral intervention. As of May 2013, 91\% of American adults own a mobile phone and $56 \%$ of American adults own a smartphone of some kind [15].

In middle-aged adults, mobile technology has recently been shown to enhance weight loss [16,17]. For example, Ma et al. sought to evaluate the effectiveness of two adapted diabetes prevention program lifestyle interventions in overweight or obese adults [16]. Two hundred forty-one adults with a mean age of 52.9 (10.6) years were randomized to one of three groups 1) Coach-led group intervention, 2) Self-directed DVD intervention or 3) usual care group. Results at 15 months demonstrate the mean change in BMI in the coach-led group was $-2.2( \pm 0.3)$ (vs. usual care, $\mathrm{p}=<.001)$ and $-1.6( \pm 0.3)$ in the self-directed group (vs. usual care, $\mathrm{p}=.02$ ). Although weight loss in the self-directed group was less than in the coach-led group, the resources needed to deliver the intervention were significantly less, making the potential reach and, therefore, impact of the intervention greater.

An additional study examined whether a mobile technology system and telephone coaching add to standard treatment improved weight loss outcomes compared to standard treatment alone [17]. Sixty-nine adults with a mean age of 57.7 years (sd 11.9) were randomized to one of the two groups. Participants in the standard plus mobile group lost $3.9 \mathrm{~kg}$ more than the standard group. Although the results of both studies above demonstrate that weight loss can be achieved and potentially augmented through use of technology as a mode intervention delivery, each included only middle aged and older adults.

The Cell Phone Intervention for You (CITY) study is a comparative effectiveness trial in which we test and compare the effect on weight loss of 1) a novel behavioral weight loss intervention that is delivered almost entirely via a mobile phone application; and 2) a behavioral intervention delivered through personal coaching calls enhanced by self-monitoring via cell phone, each compared to 3) a usual care, advice-only control group. We hypothesize that each behavioral intervention will be superior to control. Although we will compare the two behavioral interventions to each other, we make no a priori hypothesis about which will be superior. 
The results from the CITY study will provide an opportunity to 1) evaluate the impact of a personal coaching intervention on weight loss in young adults and 2) evaluate the impact of a behavioral weight loss intervention delivered via mobile phone in young adults. The result of this comparison has the potential to address whether human interaction is necessary for young adults to achieve weight loss. Ultimately, the results of the study will have implications for the design and implementation of future weight loss interventions in young adults.

The CITY study was approved by the Institutional Review Board at Duke University, as well as an NIH-appointed Data and Safety Monitoring Board. The duration of the trial is 24 months. In this manuscript we report the design and rationale for the CITY trial.

\section{Methods}

\subsection{Overview}

The CITY study is conducted as part of the Early Adult Reduction of weight through LifestYle Intervention (EARLY) trials included in an NHLBI-sponsored cooperative agreement (NIH 5U01HL096720). The first 15 months of the project were used to conduct formative work. The results of this work have been published previously [18]. The focus of the formative work was to gather information that would inform our recruitment and marketing strategy for the trial. Six focus group discussions were conducted. Health, social image, and factors such as emotions, self-esteem, and confidence were reported as reasons to pursue weight loss. Participants highlighted physical activity, dietary intake, social support, medical intervention, and taking control (e.g. being motivated) as the best weight loss strategies. Further, participants listed the following reasons for participating in a weight loss intervention: incentives, positive outcomes, education, convenience, and social support. Lastly, ways to recruit young adults into a weight loss trial that were highlighted included incentives, advertisement, emphasizing benefits, and convenience.

Following the formative phase, we finalized the protocol and began participant recruitment for the randomized trial.

\subsection{Recruitment}

Several methods were used for participant recruitment including on-line advertising using the Duke Clinical Trials website, clinicaltrials.gov, mass mailing using geospatial maps to identify ZIP codes in three specific counties in North Carolina (Durham, Orange and Wake) where there was a high prevalence of young adults from diverse backgrounds, word of mouth and media outlets such as local news and local and college campus newspapers. Mass mailings proved to be the most successful method of recruitment. Use of social media (Facebook) did not prove to be a successful recruitment strategy.

\subsection{Study population and enrollment}

Enrollment began in December of 2010 and ended in February 2012. We enrolled and randomized 365 individuals. Individuals were eligible if they were aged 18-35 years, overweight or obese (body mass index [BMI] $\geq 25 \mathrm{~kg} / \mathrm{m}^{2}$ ) and currently using a mobile phone. For logistical reasons, participants were required to receive service from one of two mobile service providers in the Durham, Raleigh and Chapel Hill, NC area: Verizon or AT\&T.

Individuals were excluded if they were taking weight loss medications, corticosteroids or had weight loss surgery. Other exclusion criteria were primarily related to safety. For example, individuals taking medication for diabetes were excluded because the extent of safety monitoring required due to the risk of weight-loss-induced hypoglycemia and the potential need for dosage adjustments is not feasible in the context of the current trial. Specific inclusion and exclusion criteria are summarized in Table 1 . We targeted enrollment of men (often under-represented in weight loss trials) at $30 \%$, and of African Americans at 30\%. We initially targeted similar enrollment of Latinos, but reduced that goal to $6 \%$ because a large proportion of Latinos in the area were not proficient in English, which was a study inclusion criteria.

Potential participants underwent a four question prescreening assessment by telephone, Interactive Voice Response (IVR), Short Message Service (SMS), or by online survey. Questions asked at this time point assessed for age (18-35), BMI, mobile phone service provider (Verizon or AT\&T). After determining initial eligibility, participants underwent a second screening by telephone to confirm eligibility and collect baseline measurements. Those who met criteria were scheduled for a face-to-face screening visit. The purpose of the face-to-face visit was to 1) obtain written consent, 2) confirm accuracy of self-reported information gathered during prescreening assessments, 3) measure weight, height and blood pressure to confirm study eligibility, and 4) collect baseline data (physical measures and survey data). The study visit lasted approximately $2 \mathrm{~h}$. Blood samples were obtained by venipuncture after an 8-14 hour overnight fast after the screening visit and up to the morning of the randomization visit. Randomization occurred at a separate face-to-face visit within 10 weeks of the screening visit. If $>10$ weeks elapsed since screening, eligibility and baseline measurements were repeated. Randomization was stratified by gender and BMI (overweight $\left(\mathrm{BMI} \geq 25-30 \mathrm{~kg} / \mathrm{m}^{2}\right)$ vs. obese $\left(\mathrm{BMI}>30 \mathrm{~kg} / \mathrm{m}^{2}\right.$ ) with equal allocation to each of three treatment groups. The post-randomization treatment period began at the randomization visit for both the Cell Phone and Usual Care control groups. Intervention for the Personal Coaching group began within 6 weeks of randomization. Each treatment period lasts 24 months, with data collection at 6, 12, and 24 months post-randomization.

\section{Description of interventions}

Both the Cell Phone and Personal Coaching interventions are rooted in social cognitive theory [19] and techniques of behavioral self-management [20]. They also employ the Transtheoretical, or stages-of-change model [21,22], and use motivational enhancement approaches [23]. The behavioral framework for both interventions is the same. However, the intervention delivery strategies differ for each group. Participants in both the Personal Coaching and Cell Phone groups receive an Android smartphone and a Bluetooth-enabled scale that transmits weights to the study research server 
Table 1

Eligibility criteria.

Inclusion criteria

- Age 18-35 years

- $\mathrm{BMI}>25 \mathrm{~kg} / \mathrm{m}^{2}$

- English language proficiency

- Currently using a mobile phone with a monthly service plan from Verizon or AT\&T

- Intending to be available long enough to participate in a 24 month intervention

- Willing to 1) switch to the CITY android phone for the duration of the study (24 months); 2 ) add the change service contract to support the CITY programming (with reimbursement from the study); and 3) agree not to disable study software while enrolled in the study

- Weight $<440$ lbs. (upper limit of detection on study scales)

- Systolic BP at screening $<160 \mathrm{~mm} \mathrm{Hg}$ and diastolic BP $<100 \mathrm{~mm} \mathrm{Hg}$. If BP exceeds this level, participants can return for rescreening after being evaluated and treated for hypertension.

Exclusion criteria

- Past or planned (within the next 24 months) weight loss surgery (e.g. gastric bypass, lap band, or liposuction); current participation in a commercial weight loss program (e.g. Weight Watcher's, Jenny Craig); current or planned enrollment in another diet/PA/weight loss intervention study.

- Currently pregnant or gave birth within the last 6 months, currently lactating or breastfeeding within the last 3 months, actively planning pregnancy within the next 24 months

- Cardiovascular event (heart attack, stroke, episode of heart failure, or revascularization procedure) within the last 6 months.

- Current treatment for malignancy (other than non-melanoma skin cancer)

- Regular use of systemic steroids, prescription weight loss drugs, and/or diabetes medications (oral or injected). "Regular use" is defined as "taking this medication most days of the week for the previous month"

- Lives in same household with a CITY investigator or staff member

- Household member enrolled in CITY

- Unable to provide informed consent

- Investigator discretion for safety or adherence reasons

- Current treatment for eating disorder or a score of 1 or higher on the ED screening questions, or a YES response to the question: "Have you recently lost more than 15 pounds in a 3-month period?"

through the cell phone. Because both active interventions require text and data plans on the phone, participants also receive fifty-three dollars in monthly reimbursement for these costs. They are expected to use the CITY phone as their primary cell phone and carry the phone as much as possible. Participants in the Personal Coaching and Cell Phone groups have access to the same self-monitoring tools to track weight, dietary intake and physical activity in the CITY app. However, there are two important differences between the Personal Coaching and the Cell Phone interventions. First, the Personal Coaching group does not receive prompting to use the self monitoring tools whereas the Cell Phone group does throughout the study. Second, many features included in the CITY app are available only to the Cell Phone Intervention group and not to the Personal Coaching group (see Table 2 for comparison of components available to each group). The information recorded by the participants via the cell phone is available to the interventionists to monitor progress and review during each intervention encounter.

Both the Personal Coaching and Cell Phone interventions promote the same lifestyle guidelines: track weight daily, keep calories in moderation (1500-1800 kcal/d for women and $2000-2300 \mathrm{kcal} / \mathrm{d}$ for men) while following the DASH eating plan [24], obtain at least 180 min of moderate activity per week, keep records of what is eaten for at least 4 days a week and limit alcohol intake (no more than 1 drink a day for women and 2 drinks a day for men). An important difference between these interventions is the modality in which these lifestyle guidelines are promoted.

\subsection{Personal Coaching intervention}

Participants randomized to the Personal Coaching intervention group initially attend a series of six weekly group sessions followed by a monthly one-on-one coaching call from an interventionist for the remainder of the 24 month intervention. The Intervention monitoring website (embedded within the trial management website) allows recording and monitoring of attendance and make-ups to group sessions and individual phone calls. The group sessions consisted of approximately 10 to 15 participants, were led by the study interventionists and lasted two hours each. Participants weighed in at the beginning of each session. The outline for the group sessions and monthly calls included the following framework: progress check, lifestyle behavior discussions, and setting a personal goal and action planning around achieving the goal. During the lifestyle behavior discussion segment of the group sessions, specific topics were covered to set the foundation for the participants to initiate behavioral change toward weight loss. These topics included a review of lifestyle guidelines, self-monitoring, appetite awareness, goal setting, conscious eating, portion control, priority-setting, social eating, dealing with negative thoughts, stress management, meal planning, triggers and craving, and social support. During monthly calls, the topics are usually driven by the participants' specific needs and progress. The interventionists delivering the coaching calls are all trained in the Motivational Interviewing (MI) technique [23] and receive on-going training by the study intervention director (Lin) to enhance their adherence to MI techniques. Each of the coaching calls lasts approximately $20 \mathrm{~min}$. In addition, participants in the Personal Coaching group are encouraged to perform self-monitoring through the apps provided on the study cell phone. The delivery of the intervention occurs primarily through monthly coaching calls.

\subsection{Cell Phone intervention}

The Cell Phone intervention is designed to incorporate into a cell phone application (app) many similar behavioral 
Table 2

Description of the Cell Phone app components.

\begin{tabular}{|c|c|c|c|}
\hline App component & Behavioral strategies & Group & Description \\
\hline Tutorial & Skill building & $\mathrm{CP}$ & $\begin{array}{l}3-8 \text { min each of orientation and coaching tutorials on various } \\
\text { lifestyle change topics related to weight loss. }\end{array}$ \\
\hline $\begin{array}{l}\text { Live wallpaper } \\
\text { (tips, links, facts) }\end{array}$ & $\begin{array}{l}\text { Skill building, visual } \\
\text { reminder, feedback }\end{array}$ & $\mathrm{CP}$ & $\begin{array}{l}\text { A short message is presented periodically on the live wallpaper; } \\
\text { the messages are related to tips for healthy living, health news } \\
\text { relevant to weight loss, jokes or motivational quotes. }\end{array}$ \\
\hline Weighing & Self-Monitoring, feedback & $\begin{array}{l}\mathrm{CP} \text { (with prompting) } \\
\text { and } \mathrm{PC}\end{array}$ & $\begin{array}{l}\text { A feature to track weight. A historical weight graph is shown after } \\
\text { the participant weighs him/herself. }\end{array}$ \\
\hline $\begin{array}{l}\text { Food tracking } \\
\quad \text { (detailed \&simple foods) }\end{array}$ & Self-monitoring, feedback & $\begin{array}{l}\mathrm{CP} \text { (with prompting) } \\
\text { and } \mathrm{PC}\end{array}$ & $\begin{array}{l}\text { A detailed and simplified food tracker with which participants } \\
\text { can track everything they eat in a day, or individually track meats, } \\
\text { fruits, vegetables, sugar sweetened beverages and participants' } \\
\text { overall impressions of the healthfulness of their meals. }\end{array}$ \\
\hline Physical activity (PA) tracking & Self-monitoring, feedback & $\begin{array}{l}\mathrm{CP} \text { (with prompting) } \\
\text { and } \mathrm{PC}\end{array}$ & $\begin{array}{l}\text { A physical activity tracker encourages participants to track the } \\
\text { type and minutes of each activity throughout the day. }\end{array}$ \\
\hline $\begin{array}{l}\text { Buddy system (random } \\
\text { pairing every } 4 \text { weeks). }\end{array}$ & Social support, accountability & $\mathrm{CP}$ & $\begin{array}{l}\text { This component pairs each participant randomly and } \\
\text { anonymously each month with a "buddy" who is also a study } \\
\text { participant. Buddies can send pre-scripted messages or construct } \\
\text { their own messages from a pool of keywords. Messages can be } \\
\text { encouraging statements or advice and tips for overcoming certain } \\
\text { lifestyle challenges. Buddies can also view a basic profile of each } \\
\text { other without revealing their identity. }\end{array}$ \\
\hline Goal setting & Goal setting, action planning & $\begin{array}{l}\mathrm{CP} \text { (with prompting) } \\
\text { and } \mathrm{PC}\end{array}$ & $\begin{array}{l}\text { A goal-setting feature that allows participants to set own or select } \\
\text { from a list of pre-determined goals and to track if goal is achieved. }\end{array}$ \\
\hline Countdown & Goal setting, action planning & $\mathrm{CP}$ & $\begin{array}{l}\text { A goal-setting feature that allows participants to set a weight goal } \\
\text { to achieve before the end of the study and to receive feedback on } \\
\text { her or his progress toward that goal. }\end{array}$ \\
\hline Challenge/game & $\begin{array}{l}\text { Motivation enhancement, } \\
\text { positive re-enforcement }\end{array}$ & $\mathrm{CP}$ & $\begin{array}{l}\text { Game or challenges to encourage usage of phone or increase } \\
\text { physical activity. }\end{array}$ \\
\hline Rewards & Positive re-enforcement & $\mathrm{CP}$ & $\begin{array}{l}\text { Rewards in the form of cartoons, video links or blog entries are } \\
\text { sent to participants when they accomplish a certain level of tracking. }\end{array}$ \\
\hline
\end{tabular}

strategies that are stressed in the Personal Coaching group including self-monitoring, problem solving, relapse prevention, stimulus control, goal-setting, action-planning and progressmonitoring toward goals. The app also delivers tailored and individualized feedback. The goal of the intervention is to provide skill-training and build self-efficacy that will lead to lasting behavioral change. The Cell Phone group receives a similar intervention delivered almost entirely through the CITY Cell Phone app on the phone; the only exception is a brief "progress check" phone call from an interventionist every six months.

The cell phone app includes tutorials, tips and news, goalsetting activities, a buddy system, food and physical activity trackers, feedback and challenge games, and technical support. Each component of the app is introduced sequentially; some components are set up according to a pre-designated schedule so that participants are prompted to open a particular component at a certain time. MI principles are incorporated whenever possible.

\subsection{Control group}

Participants assigned to the Usual Care control group are given health education materials at the time of randomization, but otherwise receive no active intervention. Like the Cell Phone and Personal Coaching groups they come to the clinic for data collection visits at 6, 12 and 24 months. After the 24-month data collection visit, control participants are offered a delayed intervention consisting of 6 weekly group sessions of behavioral coaching for weight loss. During the delayed intervention, participants will learn and practice proven strategies and skills in diet and physical activity monitoring and problem solving, and receive support from group members and the interventionist.

\subsection{Measurements}

All study measurements are collected by trained, certified study personnel who are blinded to intervention assignment. Participants are reimbursed for time and travel for data collection visits. See Table 3 for a schedule of measurements, including those described below.

Weight is measured in duplicate to the nearest $0.1 \mathrm{lb}$. with the participant in light indoor clothes without shoes, using a high-quality calibrated digital scale. Height is measured in duplicate without shoes using a wall-mounted stadiometer, and recorded to the nearest $0.1 \mathrm{~cm}$. Body mass index (BMI) is calculated as the Quetelet Index: (weight $[\mathrm{kg}] /$ height $\left[\mathrm{m}^{2}\right]$ ). Waist circumference is measured in duplicate at the level of the upper iliac crest at the end of a normal exhalation, and the measurement is recorded to the nearest $0.1 \mathrm{~cm}$ [25].

Blood pressure (BP) measurements are taken using an automated oscillometric device, Omron ${ }^{\mathrm{TM}}$ HEM-907XL (OMRON Healthcare, Bannockburn, Illinois). Participants are asked to refrain from eating, exercising or smoking for at least 30 min prior to BP measurements. Arm circumference is measured to determine proper cuff size [25]. Prior to $\mathrm{BP}$ measurement, participants sit for $5 \mathrm{~min}$ in a quiet room free from activity. BP is measured in the right arm with participants in a seated position with the back supported, feet flat on the floor, and arm supported at heart level. Three measurements are obtained at 30 second intervals, and averaged. 
Table 3

Data collection schedule.

\begin{tabular}{|c|c|c|c|c|}
\hline \multirow[t]{2}{*}{ Data Collected } & \multicolumn{4}{|c|}{ Collection Time Point } \\
\hline & Baseline & 6 Months & 12 Months & 24 Months \\
\hline \multicolumn{5}{|l|}{ Self Report Measures } \\
\hline Demographics & $\mathrm{X}$ & & $\mathrm{X}$ & $\mathrm{X}$ \\
\hline Accessibility to/Use of Media/Technology & $\mathrm{X}$ & & $\mathrm{X}$ & $\mathrm{X}$ \\
\hline Smoking & $\mathrm{X}$ & & $\mathrm{X}$ & $\mathrm{X}$ \\
\hline Alcohol & $\mathrm{X}$ & & $\mathrm{X}$ & $\mathrm{X}$ \\
\hline Daily Meal Patterns & $\mathrm{X}$ & & $\mathrm{X}$ & $\mathrm{X}$ \\
\hline Eating Away from Home & $\mathrm{X}$ & & $\mathrm{X}$ & $\mathrm{X}$ \\
\hline Sugar Sweetened Beverage Consumption & $\mathrm{X}$ & & $\mathrm{X}$ & $\mathrm{X}$ \\
\hline Weight Management Practices & $\mathrm{X}$ & & $\mathrm{X}$ & $\mathrm{X}$ \\
\hline Global Physical Activity Questionnaire & $\mathrm{X}$ & $\mathrm{X}$ & $\mathrm{X}$ & $\mathrm{X}$ \\
\hline Paffenbarger Exercise Habits Questionnaire & $\mathrm{X}$ & $\mathrm{X}$ & $\mathrm{X}$ & $\mathrm{X}$ \\
\hline Physical Activity Neighborhood Environment & $\mathrm{X}$ & & $\mathrm{X}$ & $\mathrm{X}$ \\
\hline Sedentary Behavior Questionnaire (weekday and weekend day) & $\mathrm{X}$ & & $\mathrm{X}$ & $\mathrm{X}$ \\
\hline Sleep & $\mathrm{X}$ & & $\mathrm{X}$ & $\mathrm{X}$ \\
\hline Depression (CESD-10) & $\mathrm{X}$ & $\mathrm{X}$ & $\mathrm{X}$ & $\mathrm{X}$ \\
\hline Perceived Stress & $\mathrm{X}$ & & $\mathrm{X}$ & $\mathrm{X}$ \\
\hline Self-Efficacy (Diet, PA, Technology) & $\mathrm{X}$ & & $\mathrm{X}$ & $\mathrm{X}$ \\
\hline Self-Esteem/Body Image (Stunkard) & $\mathrm{X}$ & & $\mathrm{X}$ & $\mathrm{X}$ \\
\hline Social Support & $\mathrm{X}$ & & $\mathrm{X}$ & $\mathrm{X}$ \\
\hline \multicolumn{5}{|l|}{ Self Report Measures Cont. } \\
\hline Stigma & $\mathrm{X}$ & & $\mathrm{X}$ & $\mathrm{X}$ \\
\hline ASA24 & $\mathrm{X}$ & $\mathrm{X}$ & $\mathrm{X}$ & $\mathrm{X}$ \\
\hline \multicolumn{5}{|l|}{ Physical Measurements } \\
\hline Height & $\mathrm{X}$ & & $\mathrm{X}$ & $\mathrm{X}$ \\
\hline Weight & $\mathrm{X}$ & $\mathrm{X}$ & $\mathrm{X}$ & $\mathrm{X}$ \\
\hline Body Mass Index (BMI) & $\mathrm{X}$ & $\mathrm{X}$ & $\mathrm{X}$ & $\mathrm{X}$ \\
\hline Waist Girth & $\mathrm{X}$ & & $\mathrm{X}$ & $\mathrm{X}$ \\
\hline Arm Circumference & $\mathrm{X}$ & $\mathrm{X}$ & $\mathrm{X}$ & $\mathrm{X}$ \\
\hline Resting Blood Pressure & $\mathrm{X}$ & $\mathrm{X}$ & $\mathrm{X}$ & $\mathrm{X}$ \\
\hline Resting Heart Rate & $\mathrm{X}$ & $\mathrm{X}$ & $\mathrm{X}$ & $\mathrm{X}$ \\
\hline \multicolumn{5}{|l|}{ Labs } \\
\hline Blood Collection for Storage/Banking & $\mathrm{X}$ & & $\mathrm{X}$ & $\mathrm{X}$ \\
\hline Buffy Coat Collection for Storage/Banking & $\mathrm{X}$ & & & \\
\hline Blood Collection: Lipids, Insulin, Glucose & $\mathrm{X}$ & & $\mathrm{X}$ & $\mathrm{X}$ \\
\hline Blood Collection: Pregnancy Test & $\mathrm{X}$ & & & \\
\hline \multicolumn{5}{|l|}{ Staff Administered Measures } \\
\hline Medication Use and Medication Tracking & $\mathrm{X}$ & $\mathrm{X}$ & $\mathrm{X}$ & $\mathrm{X}$ \\
\hline Medical Events & $\mathrm{X}$ & $\mathrm{X}$ & $\mathrm{X}$ & $\mathrm{X}$ \\
\hline Eating Disorders Questions & $\mathrm{X}$ & $\mathrm{X}$ & $\mathrm{X}$ & $\mathrm{X}$ \\
\hline
\end{tabular}

After an overnight fast ( $8-12 \mathrm{~h})$, blood is obtained by venipuncture. Serum is sent to a commercial clinical lab (LabCorp, Research Triangle Park, NC) for chemical analysis of glucose, insulin and lipid levels. Insulin and glucose results are used to calculate the Homeostasis Model Assessment (HOMA) index, a reflection of insulin resistance [26]. Serum, plasma and buffy coat samples are banked for future analysis.

Dietary intake is assessed using the NCI ASA 24, which is an NIH-sponsored, free, web-based software tool that enables automated and self-administered 24-hour dietary recalls [27]. Two diet recalls are completed by participants at each time dietary intake is assessed. Additional diet-related questions assess 1) consumption of sugar-sweetened beverages; 2) consumption of alcohol; 3) frequency of eating away from home; 4) daily meal patterns; and 5) weight management strategies. Physical activity is assessed by the Global Physical Activity Questionnaire (GPAQ) [28,29] which has been validated in diverse populations, and by the Paffenbarger physical activity questionnaire [[30]. Additional physical activity questions measure 1) sedentary behavior; 2) sleep habits; and 3) physical environment.
Psychosocial questionnaires measure 1) depressive symptoms using the validated CES-D [[31]; 10 (a subset of the 20-item scale); 2) perceived stress using the 4-item "Perceived Stress Scale" (PSS) (a subset of the14-item scale) [32]; 3) body image and body satisfaction, using the graphical questionnaire of Stunkard [33]; 4) self-efficacy for changing diet, PA and weight; 5) social support using the Multidimensional Perceived Social Support (MSPSS) questionnaire [34]; and 6) perceived stigmatization related to obesity $[35,36]$. Additional questionnaires measure demographic information, medical history, smoking history and current medications. Last, a technology usage questionnaire measures types and frequency of use of communications and social networking technologies.

\subsection{Analysis plan}

The primary analysis will be based on intention-to-treat principles. The outcome for the two main study hypotheses (Personal Coaching vs. Control and Cell Phone vs. Control) is absolute weight change in kilograms at 12 months. A constrained longitudinal data analysis model (cLDA) will be 
used to estimate changes in absolute weight over time and test the primary hypotheses [37]. The variables in the model will include dichotomous stratification factors (overweight vs. obese, and male vs. female), a time effect, and the treatment by time interaction.

Virtually all of the other study outcomes (change in blood pressure, insulin resistance, lipids, nutritional intake, and psychosocial factors) are continuous and longitudinal; therefore, they will be analyzed using the cLDA modeling approach described above. For analyses focusing on consistency of weight control across subgroups of interest (e.g., by race or gender), analyses will be conducted by adding the subgroup variable and its interaction with the treatment indicator to the statistical models described above. The interaction term will be tested to determine if the treatment effect is consistent across the levels of the subgroup variable. To maintain an overall type I error rate of 0.05 for the analysis of the primary hypotheses, the Holm sequential testing procedure will be used. All secondary and additional exploratory analyses will be evaluated at the standard 0.05 significance level.

Power and sample size calculations were based on estimates from the Weight Loss Maintenance trial (WLM) [7,25] and the Trials of Hypertension Prevention (TOHP) [38] studies. A common standard deviation of weight of $16.6 \mathrm{~kg}$ at baseline, a correlation between successive weight measurements within the same individual of 0.8 , and attrition in each group of up to $25 \%$ by 24 months were used. Calculations further reflected the assumption that the control group will gain approximately $1.5 \mathrm{~kg}$ per year. With 120 participants randomized to each of the three intervention arms and a type I error rate (alpha) of 0.025 (to reflect use of the Holm sequential testing procedure), there is more than $80 \%$ power to detect a difference in weight of $5 \mathrm{~kg}$ or greater between Cell Phone and Control or Personal Coaching and Control.

\section{Discussion}

CITY is part of a consortium of 7 trials addressing weight control in 18 to 35 year olds. To date there are few large, randomized controlled weight loss interventions focused specifically on young adults. If effective, implementation of the CITY interventions could mitigate the alarming rates of obesity in young adults.

As noted by Rao and Kirley, to affect the obesity epidemic, weight management programs must be convenient, accessible, affordable, scalable, and sustainable; programs meeting these criteria can have significant impact on health outcomes even if the effect on weight is modest [39]. These criteria may be best met using mobile technologies.

Mobile phones create novel healthcare opportunities because the phones can be used to deliver and gather tailored health-related information and to broadly disseminate interventions in free-living conditions. Although motivation, incentive, and uptake of different strategies may differ by age, the development of weight loss interventions for young adults could logically build on interventions that have been successful in older age groups. However, there is a lack of data regarding the design and delivery of weight loss interventions to young adults via mobile phone technology.
In designing the personal coaching intervention we combined both the traditional effective personal contact from the Weight Loss Maintenance trial (WLM) [7,25], which was delivered efficiently by trained interventionists, and a cell phone technology for self-monitoring. In the Weight Loss Maintenance trial, personal counseling delivered mostly by phone was superior to an internet intervention and to the absence of a maintenance intervention for maintaining weight loss [9].

In other settings, telephone contact has been shown to be effective in improving medication adherence [40,41] and enhancing diet adherence [42]. When phone counseling is combined with self-monitoring, the impact on health outcomes is enhanced [41]. The use of personal counseling delivered by telephone allows individualized, personal interaction without the costs of transportation and facilities that accompany in-person programs. Personal interaction allows the intervention to be adapted and tailored to participants' current concerns, health goals, and specific barriers to achieving these goals. However, this model for delivering behavioral intervention still relies on professional interventionists, and is therefore not sufficiently scalable to address the extensive obesity epidemic.

The Cell Phone intervention has the potential to be disseminated very broadly among young adults, using technology with tremendous potential for economy of scale. The design of the $\mathrm{CP}$ intervention integrates the essential elements of a successful weight loss intervention into a cell phone application. The design also incorporates flexibility in the mode and timing of delivery of information and feedback.

\subsection{Challenges and solutions}

There were multiple challenges we faced in recruitment, enrollment and the design and implementation of the intervention. The remainder of the discussion is focused on the major challenges we have faced and how we overcame those challenges.

\subsection{Challenges related to recruitment of diverse participants}

Our original goal was to include 30\% African Americans and $10 \%$ Latinos in the study. In order to meet these goals we utilized investigator relationships with the community partners. In addition, we consulted geospatial mapping data in order to target mailings to areas that have a diverse population. Enrollment of 10\% Latinos proved to be difficult therefore we revised our enrollment goal to include $6 \%$ Latinos.

We also targeted recruitment in order to achieve enrollment of $30 \%$ men. In order to meet this goal we included male participants in public interviews about the study and targeted mailings to areas with a high prevalence of men.

\subsection{Challenges related to the personal coaching intervention}

In order to maximize attendance at group sessions we incorporated practical information and demonstrations during the sessions and were flexible about timing of the sessions. We recognized that participants might experience a lack of social support after the six in person group sessions were complete. Accordingly, we coordinated and encouraged group activities 
throughout the intervention and integrated video story sharing via a specific application among participants.

\subsection{Challenges related to the Cell Phone intervention}

One of the challenges we faced in development of the intervention was how to adapt the intervention over time. Our solution was to incorporate participant feedback in the development process.

Another challenge we faced was how to keep participants engaged in the Cell Phone intervention and using the app. The literature regarding how often one needs to use a weight loss app to achieve successful weight loss is lacking. However, we sought to maximize opportunities for engagement of the Cell Phone group with the app. Accordingly, we developed algorithms to send prompts to the Cell Phone group based on application use history. Further, we utilized campaigns and competitions among special groups to enhance engagement. Lastly, we built in alerts so that when the application is not used an automated message prompts the participant to resume use.

Another challenge we encountered was related to frequent changes in cell phone models and software versions. The ever changing landscape of mobile technology has required us to adapt the study phone app to accommodate new phone models and upgrades in operating systems.

\subsection{Challenges related to the Usual Care group}

The biggest challenge we anticipate with the Usual Care group is retention. Accordingly we built into the protocol incentives for data completion in order to maximize retention in this group.

Overall, we anticipate the solutions we put in place to address the above challenges will lead to retention of study participants and sustained engagement in the intervention.

\section{Conclusions}

Addressing the obesity epidemic will require a range of strategies and interventions. One of these strategies involves a focus on young adults in order to establish weight control early in adult life and prevent CVD risk factors in later life. In this population, mobile technology may be particularly effective. Implications for more weight loss in the Cell Phone as compared to Personal Coaching group include the possibility that the app provides individuals flexible and easy access to intervention components and feedback. Implications for more weight loss in the Personal Coaching as compared to Cell Phone group include the possibility that human interaction and coaching lead to more effective goal setting and action planning. The sample size, diversity of the study population with regard to age (within the young-adult range), sex, and race, and duration of follow-up (24 months) will permit reasonable generalization, with important implications for implementation.

\section{Conflicts}

Steven C. Grambow reported that he currently receives consulting fees from Gilead Sciences for serving on multiple Data and Safety Monitoring Boards (DSMBs). Although the relationship is not perceived to represent a conflict with the present work, it has been included in the spirit of full disclosure.

\section{Acknowledgments}

The authors would like to take the time to thank the CITY study participants and the CITY study research team. Study data were collected and managed using REDCap (Research Electronic Data Capture) [43] electronic data capture tools hosted at Duke University. REDCap (Research Electronic Data Capture) is a secure, web-based application designed to support data capture for research studies providing: 1) an intuitive interface for validated data entry; 2) audit trails for tracking data manipulation and export procedures; 3) automated export procedures for seamless data downloads to common statistical packages; and 4) procedures for importing data from external sources. The trial was sponsored by the National Heart, Lung, and Blood Institute grant \# 5U01HL096720.

\section{References}

[1] Flegal KM, Carroll MD, Kit BK, Ogden CL. Prevalence of obesity and trends in the distribution of body mass index among US adults, 19992010. JAMA 2012;307:491-7.

[2] Burke GL, Bild DE, Hilner JE, Folsom AR, Wagenknecht LE, Sidney S. Differences in weight gain in relation to race, gender, age and education in young adults: the CARDIA Study. Coronary Artery Risk Development in Young Adults. Ethn Health 1996;1:327-35.

[3] Lewis CE, Jacobs Jr DR, McCreath H, Kiefe CI, Schreiner PJ, Smith DE, et al. Weight gain continues in the 1990s: 10-year trends in weight and overweight from the CARDIA Study. Coronary Artery Risk Development in Young Adults. Am J Epidemiol 2000;151:1172-81.

[4] Lloyd-Jones DM, Liu K, Colangelo LA, Yan LL, Klein L, Loria CM, et al. Consistently stable or decreased body mass index in young adulthood and longitudinal changes in metabolic syndrome components: the Coronary Artery Risk Development in Young Adults Study. Circulation 2007;115:1004-11.

[5] Loria CM, Liu K, Lewis CE, Hulley SB, Sidney S, Schreiner PJ, et al. Early adult risk factor levels and subsequent coronary artery calcification: the CARDIA Study. J Am Coll Cardiol 2007;49:2013-20.

[6] Liu K, Daviglus ML, Loria CM, Colangelo LA, Spring B, Moller AC, et al. Healthy lifestyle through young adulthood and the presence of low cardiovascular disease risk profile in middle age: the Coronary Artery Risk Development in (Young) Adults (CARDIA) study. Circulation 2012;125:996-1004.

[7] Hollis JF, Gullion CM, Stevens VJ, Brantley PJ, Appel LJ, Ard JD, et al. Weight loss during the intensive intervention phase of the weight-loss maintenance trial. Am J Prev Med 2008;35:118-26.

[8] Hebden L, Chey T, Allman-Farinelli M. Lifestyle intervention for preventing weight gain in young adults: a systematic review and meta-analysis of RCTs. Obes Rev 2012;13:692-710.

[9] Svetkey LP, Stevens VJ, Brantley PJ, Appel LJ, Hollis JF, Loria CM, et al. Comparison of strategies for sustaining weight loss: the weight loss maintenance randomized controlled trial. JAMA 2008;299:1139-48.

[10] Svetkey LP, Clark JM, Funk K, Corsino L, Batch BC, Hollis JF, et al. Greater weight loss with increasing age in the weight loss maintenance trial. Obesity January 2014;22(1):39-44.

[11] Poobalan AS, Aucott LS, Precious E, Crombie IK, Smith WC. Weight loss interventions in young people (18 to 25 year olds): a systematic review. Obes Rev 2010;11:580-92.

[12] Greaney ML, Less FD, White AA, Dayton SF, Riebe D, Blissmer B, et al. College students' barriers and enablers for healthful weight management: a qualitative study. J Nutr Educ Behav 2009;41:281-6.

[13] Andajani-Sutjahjo S, Ball K, Warren N, Inglis V, Crawford D. Perceived personal, social and environmental barriers to weight maintenance among young women: a community survey. Int J Behav Nutr Act 2004;1:15.

[14] Strong KA, Parks SL, Anderson E, Winett R, Davy BM. Weight gain prevention: identifying theory-based targets for health behavior change in young adults. J Am Diet Assoc 2008;108:1708-15.

[15] J B. Highlights of the Pew Internet Project's research related to mobile technology; 2013. 
[16] Ma J, Yank V, Xiao L, Lavori PW, Wilson SR, Rosas LG, et al. Translating the Diabetes Prevention Program lifestyle intervention for weight loss into primary care: a randomized trial. JAMA 2013;173:113-21.

[17] Spring B, Schneider K, McFadden HG, Vaughn J, Kozak AT, Smith M, et al. Multiple behavior changes in diet and activity: a randomized controlled trial using mobile technology. Arch Intern Med 2012;172:789-96.

[18] Corsino L, Lin PH, Batch BC, Intille S, Grambow SC, Bosworth HB, et al. Recruiting young adults into a weight loss trial: report of protocol development and recruitment results. Contemp Clin Trials 2013;35:1-7.

[19] Bandura A. Social foundations of thought and action: a social cognitive theory. Englewood Cliffs, NJ: Prentice Hal; 1986.

[20] Watson DT. Self-directed behavior: self-modification for personal adjustment. 5th ed. Pacific Grove, CA: Brooks/Cole; 1989.

[21] Prochaska JO, Velicer WF, Rossi JS, Goldstein MG, Marcus BH, Rakowski $\mathrm{W}$, et al. Stages of change and decisional balance for 12 problem behaviors. Health Psychol 1994;13:39-46.

[22] Prochaska JO, DiClemente CC. Stages and processes of self-change of smoking: toward an integrative model of change. J Consult Clin Psychol 1983;51:390-5

[23] Miller WR, Rollnick S. Motivational interviewing : preparing people for change. 2nd ed. Guilford Press; 2002.

[24] Appel LJ, Moore TJ, Obarzanek E, Vollmer WM, Svetkey LP, Sacks FM, et al. A clinical trial of the effects of dietary patterns on blood pressure DASH Collaborative Research Group. N Engl J Med 1997;336:1117-24.

[25] Brantley P, Appel L, Hollis J, Stevens V, Ard J, Champagne C, et al. Design considerations and rationale of a multi-center trial to sustain weight loss: the Weight Loss Maintenance Trial. Clin Trials 2008;5:546-56.

[26] Bonora E, Targher G, Alberiche M, Bonadonna RC, Saggiani F, Zenere $\mathrm{MB}$, et al. Homeostasis model assessment closely mirrors the glucose clamp technique in the assessment of insulin sensitivity: studies in subjects with various degrees of glucose tolerance and insulin sensitivity. Diabetes Care 2000;23:57-63.

[27] Automated Self-administered 24-hour Dietary Recall (ASA24).

[28] Bull FC, Maslin TS, Armstrong T. Global physical activity questionnaire (GPAQ): nine country reliability and validity study. J Phys Act Health 2009;6:790-804.

[29] Trinh OT, Nguyen ND, van der Ploeg HP, Dibley MJ, Bauman A. Testretest repeatability and relative validity of the Global Physical Activity Questionnaire in a developing country context. J Phys Act Health 2009;6(Suppl. 1):S46-53.

[30] Paffenbarger Jr RS, Hyde RT, Wing AL, Hsieh CC. Physical activity, all-cause mortality, and longevity of college alumni. N Engl J Med 1986;314:605-13.
[31] Brantley PJ, MDJ, Thomas JL. The Beck Depression Inventory (BDI) and the Center for Epidemiologic Studies Depression Scale (CES-D). Mahwah, NJ: Lawrence Erlbaum Associates, Inc; 2000.

[32] Cohen S, Kamarck T, Mermelstein R. A global measure of perceived stress. J Health Soc Behav 1983;24:385-96.

[33] Stunkard AST, Schulsinger F. Use of the Danish Adoption Register for the study of obesity and thinness. In: Kety SRI, Sidman R, Matthysse S, editors. The Genetics of Neurological and Psychiatric Disorders. New York: Raven Press; 1983.

[34] Canty-Mitchell J, Zimet GD. Psychometric properties of the Multidimensional Scale of Perceived Social Support in urban adolescents. Am J Community Psychol 2000;28:391-400.

[35] Williams DR, Yan Y, Jackson JS, Anderson NB. Racial differences in physical and mental health: socio-economic status stress and discrimination. J Health Psychol 1997;2:335-51.

[36] Chae DH, Takeuchi DT, Barbeau EM, Bennett GG, Lindsey J, Krieger N. Unfair treatment, racial/ethnic discrimination, ethnic identification, and smoking among Asian Americans in the National Latino and Asian American Study. Am J Public Health 2008;98:485-92.

[37] Liu GF, Lu K, et al. Authors reply to comments on "Should baseline be a covariate or dependent variable in analyses of change from baseline in clinical trials?". Stat Med 2010;29:1457.

[38] The effects of nonpharmacologic interventions on blood pressure of persons with high normal levels. Results of the Trials of Hypertension Prevention, Phase I. JAMA 1992;267:1213-20.

[39] Rao G, Kirley K. The future of obesity treatment: comment on "Integrating technology into standard weight loss treatment: a randomized controlled trial". JAMA 2013;173:111-2.

[40] Friedman RH, Kazis LE, Jette A, Smith MB, Stollerman J, Torgerson J, et al. A telecommunications system for monitoring and counseling patients with hypertension. Impact on medication adherence and blood pressure control. Am J Hypertens 1996;9:285-92.

[41] Bosworth HB, Olsen MK, Gentry P, Orr M, Dudley T, McCant F, et al. Nurse administered telephone intervention for blood pressure control: a patient-tailored multifactorial intervention. Patient Educ Couns 2005;57:5-14.

[42] Resnicow K, Jackson A, Wang T, De AK, McCarty F, Dudley WN, et al. A motivational interviewing intervention to increase fruit and vegetable intake through Black churches: results of the Eat for Life trial. Am J Public Health 2001;91:1686-93.

[43] Harris PATR, Thielke R, Payne J, Gonzalez N, Conde JG. Research electronic data capture (REDCap) - a metadata-driven methodology and workflow process for providing translational research informatics support. J Biomed Inform 2009;42:377-81. 